\title{
Durability of beams with hybrid reinforcement from metal and basalt fiber reinforced polymer (BFRP) armature
}

\author{
Alexander Valovoi ${ }^{1, *}$, Peter Koval ${ }^{2}$, Alexander Eremenko ${ }^{1}$, Maksim Valovoi ${ }^{1}$, and \\ Sergei Volkov ${ }^{1}$ \\ ${ }^{1}$ Kryvyi Rih National University, Vitaly Matusevich Str. 11, Kryvyi Rih, Ukraine, 50036. \\ ${ }^{2}$ National academy of fine arts and architecture, Voznesensk Privoz Str.20, Kyiv, Ukraine, 04053.
}

\begin{abstract}
The article presents the program and the results of experimental tests of beam samples with metal, basalt fiber reinforced polymer (BFRP) and hybrid (metal and BFRP) reinforcement. The samples were made of standard concrete with quartz sand as the fine aggregate and concrete with fine fraction wastes of a mining and beneficiation complex (MBC) used instead of the sand. Short-run tests of the beams under monotonous static loading until destruction enabled the conclusion that durability of the BFRP reinforced beams increased by $37-44 \%$ as compared to the metal reinforced beams. When hybrid reinforcing, reduction of the (BFRP) content did not produce an effect on decrease of durability indices; durability gains compared to the beams reinforced by metal made $38-41 \%$. In the BFRP reinforced beams, due to the absence of plastic deformations in this reinforcement, there were no residual deformations after cessation of loading despite significant damage and deterioration of the concrete. Samples of beams made of concrete on fine fraction wastes of MBC, showed $1-8 \%$ higher strengths in comparison with similar beams made of concrete with quartz sand as the fine aggregate.
\end{abstract}

\section{Introduction}

Composite reinforcement is known to possess high tensile strength, but a lower modulus of elasticity as compared with steel [1-3]. It was found [2-8] that the experimental samples showed a significant increase in durability, by $25-90 \%$, vs. the samples reinforced by metal armature. Due to the low modulus of elasticity, the deformability of the samples reinforced by BFRP was higher. Thus, in [8], it is stated that the deflections and width of cracks in bended samples, reinforced by composite armature, were $60 \%$ higher than those reinforced by metal reinforcement, at a stress level of $70 \%$ of the destructive one. Similar results were obtained in the works [2-10, 11].

It should be noted that the increased deformability of structures is specific both for (BFRP), and for glass fiber reinforced polymer (GFRP) [9, 10].

One of the ways to reduce the deformability of bending structures, reinforced with BFRP armature, is to use mixed (hybrid) reinforcement, in which both the BFRP armature and the metal one are placed in the stretched zone at the same time. In this case, the metal armature should provide the required level of deflection and crack resistance, and the BFRP

* Corresponding author: valovojua@gmail.com 
armature should increase the cross-section strength and reduce the destructive impact of the aggressive environment on the overall bearing ability of the structure.

At present, there is a very limited base of experimental data on the work of such hybrid reinforced structures. In particular, existing research works do not clarify the question of how the percentage reduction of BFRP armature in hybrid reinforcement impacts the strength values of prototype samples.

\section{Test program}

The experimental tests were carried out in the laboratory of the Civil Engineering faculty at Kryvyi Rih National University, Ukraine.

\subsection{Examples}

The program of experimental tests provided production of 6 series of concrete reinforced beams samples, with three beams in each series. Samples by the series differed in the following features:

- the BM series - beams reinforced by metal armature (control series);

- the BB series - beams reinforced by BFRP armature;

- the BMB series - beams with hybrid reinforcement with metal and BFRP armature;

-the BMD series - beams reinforced by metal armature using concrete on fine wastes of mining and beneficiation complex (MBC);

- the BBD series - beams reinforced by BFRP using concrete with fine wastes of MBC;

- the BMBD series - beams with hybrid reinforcement by metal and BFRP armature using concrete with fine wastes of MBC.

Reinforcement of cross-sections of beams of the series is given in Table 1.

To provide correct comparison of the test results of beams of different series, the sizes of the cross sections of the beams and the percentage of their reinforcement were assumed to be unchanged for the samples of all series. The pattern of reinforcing samples of beams is shown in Fig. 1.

Manufacturing of armature grating, concrete mixture and concreting of experimental samples of beams took place at the PJSC "Kryvorizhindustrbud", Ukraine. Concreting of experimental samples of beams and cubes was carried out in metallic forms.

a)
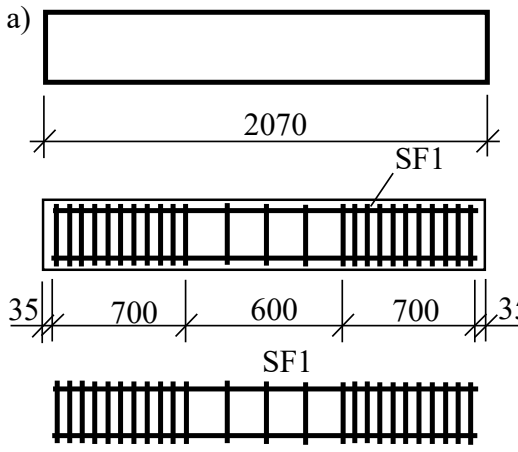
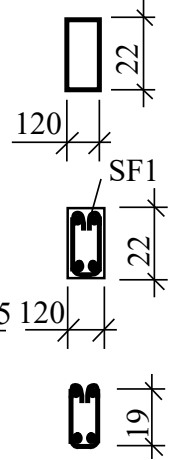
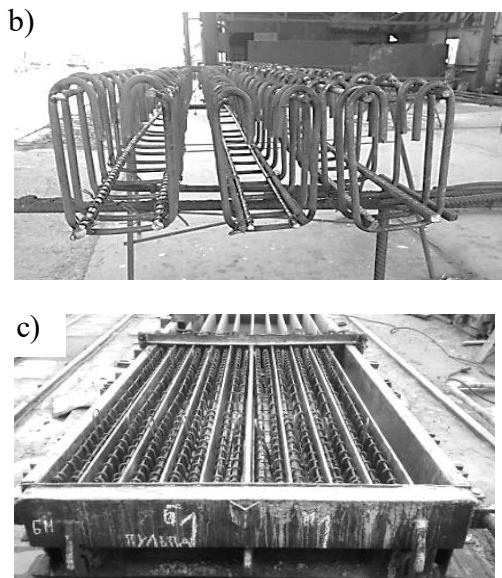

Fig. 1. Reinforcement of samples of beams: a) Framing armature drawings of beams of BM series; b) Armature grating of beams; c) Framing forms of beams; SF - space framework. 
Table1. Reinforcement pattern of cross sections of beams by series.

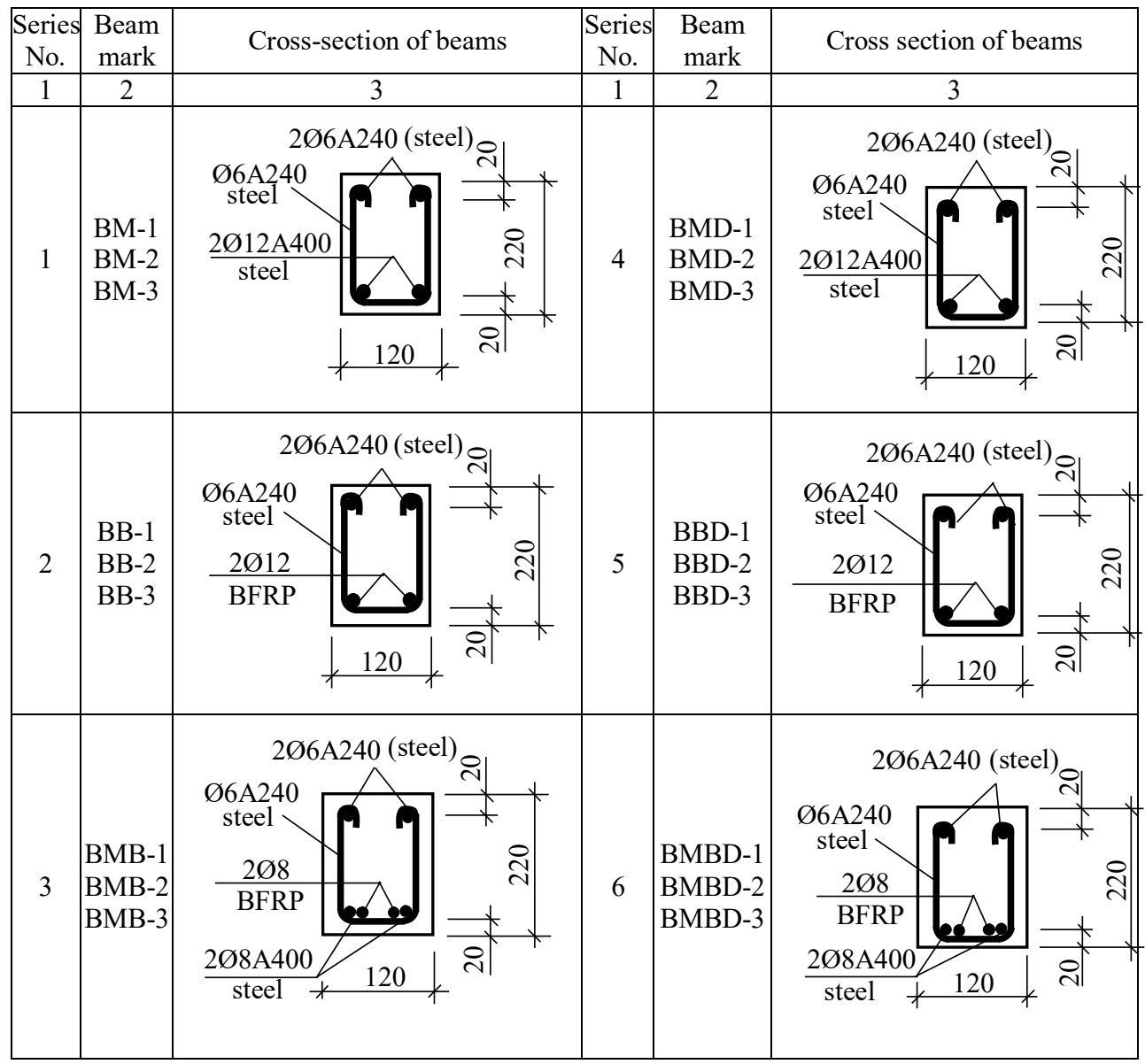

Before concreting the surface of the forms was greased with a thin layer of hydrophobic lubricant. Joined spatial gratings were installed in the forms. The designed position of the gratings was provided with the help of concrete linings to ensure the formation of the protective layer of concrete. The preparation of a concrete mixture was carried out at a concrete-soluble knot. Placing the mixture into the formwork was carried out using a bucket with subsequent seal on the vibration table (Fig. 2). After forming, the samples were placed in a heating chamber. The form was removed 28 days after concreting.

a)

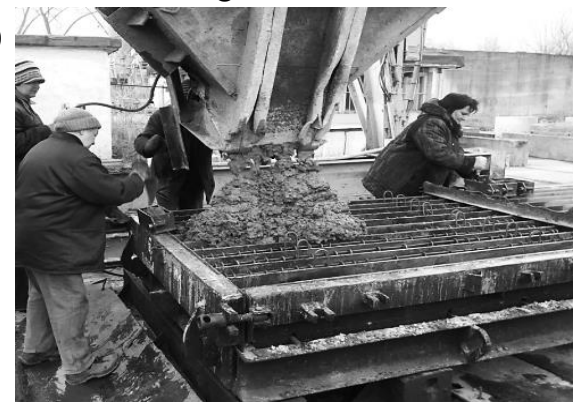

b)

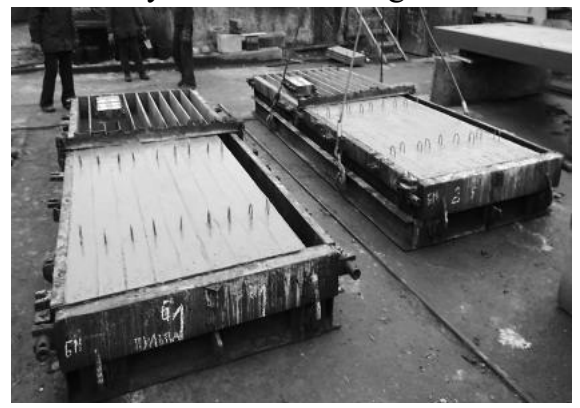

Fig. 2. Samples of beams manufacturing: a) laying of concrete mixture; b) general view of concreted samples. 


\subsection{Materials}

For reinforcing samples, metal and BFRP armature were used in accordance with the reinforcement schemes shown in Table. 1. BFRP armature was provided by the manufacturer of composite armature LLC "Technobazalt-Invest", Ukraine.

Mechanical characteristics of the armature are given in the Table 2.

Table 2. Mechanical characteristics of armature for samples of beams.

\begin{tabular}{|l|c|c|c|c|}
\hline $\begin{array}{c}\text { Armature } \\
\text { class }\end{array}$ & $\begin{array}{c}\text { The boundary } \\
\text { of fluidity, } \\
\mathrm{N} / \mathrm{mm}^{2}\end{array}$ & $\begin{array}{c}\text { Temporary resistance } \\
\text { to breaking, } \\
\mathrm{N} / \mathrm{mm}^{2}\end{array}$ & $\begin{array}{c}\text { Modulus of } \\
\text { elasticity, } \\
\mathrm{N} / \mathrm{mm}^{2}\end{array}$ & $\begin{array}{c}\text { Relative elongation } \\
\text { after breaking, } \\
\%\end{array}$ \\
\hline A400C (steel) & 400 & 500 & $200 \times 10^{3}$ & 16 \\
\hline A240 (steel) & 240 & 370 & $200 \times 10^{3}$ & 25 \\
\hline BFRP & - & 800 & $45 \times 10^{3}$ & 1.78 \\
\hline
\end{tabular}

Concrete of class $\mathrm{C} 25 / 30$ made at a concrete-soluble knot was used for concreting. As mentioned above, for concreting beams of series BM, BB, BMB concrete with quartz sand as a fine aggregate was used. In the beams of the series BMD, BBD, BMBD we used concrete on fine $\mathrm{MBC}$ wastes which are a fractionated quartz-glandular mineral mixture with the density of $1500-1600 \mathrm{~kg} / \mathrm{m}^{3}$. The actual use of MBC wastes as a fine aggregate for concrete mixture is economically justified (MBC wastes cost 8-10 times less than quartz sand) and in part, it allows solving the issues of industrial wastes recycling.

The numerous studies [12] of the past decades indicate the possibility of equivalent replacement of quartz sand by fine wastes of $\mathrm{MBC}$ when manufacturing a wide range of reinforced concrete products.

In order to determine the strength and deformation characteristics of the concrete types used, there was carried out concreting of samples of cubes $(100 \times 100 \times 100 \mathrm{~mm})$ of each concrete type simultaneously with concreting beams. Tests of concrete samples were performed both at the age of 28 days and at the age of 151 days after their manufacturing, immediately before testing the samples of the beams. At the age of 28 days the compression strength of both types of concrete corresponded to the accepted designed class of concrete $(\mathrm{C} 25 / 30)$. At the age of 151 days it was $46.16 \mathrm{~N} / \mathrm{mm}^{2}$ for concrete on quartz sand and $51.72 \mathrm{~N} / \mathrm{mm}^{2}$ for concrete on fine $\mathrm{MBC}$ wastes.

\subsection{Tests of the samples}

Testing of beams was carried out on a hydraulic press P-125 according to the scheme of a single-run free beam loaded with two lumped forces in the thirds of gear. During the testing the following devices were used: the Maximov deflection indicator; engineer's dial gauge with a price of $0.01 \mathrm{~mm}$ readability for determining the deformations of beam concrete and sitting beams bearing supports; the MPB- 2 microscope with a $24 \mathrm{x}$ magnification and 0.05 $\mathrm{mm}$ readability to determine the width of the opening of normal and inclined cracks.

The loading of tested beams was carried out by 0.1 of the ultimate breaking load. The program of experimental tests provided for determination of strength, rigidity and crack resistance of test samples which conditioned use of the above-mentioned devices. The stand for testing the beams for bending and its scheme are shown in Fig. 3. 
a)

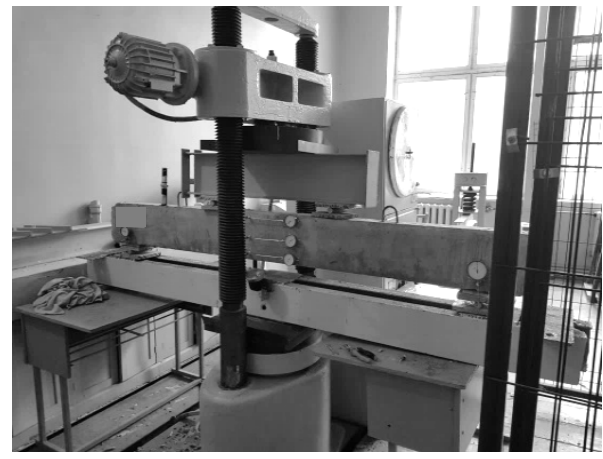

b)

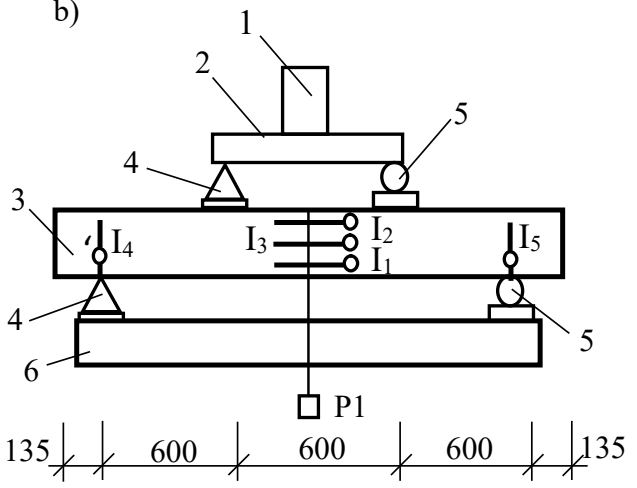

Fig. 3. a) Stand for testing of beams; b) Plant for testing of beams 1 - press plate; 2 - traverse upper distributive; 3 - experimental beam; 4 - fixed bearing support; 5 - moving traverse; 6 - lower traverse; $\mathrm{I}_{1}, \mathrm{I}_{2}, \mathrm{I}_{3}, \mathrm{I}_{4}, \mathrm{I}_{5}$ - engineer's dial gauge of $0.01 \mathrm{~mm}$ readability; P1 - the Maximov deflection indicator of $0.1 \mathrm{~mm}$ readability.

\section{Results and discussion}

The work of experimental samples of beams under load and their destruction were in direct dependence on the applied type of reinforcement.

Beams of the series BM, BMD showed the work and nature of destruction typical for beams reinforced by metal armature. With $0.3-0.4$ of the destructive load, the first normal cracks began to form in the concrete in the zone of pure bending. The further load increase resulted in the formation of new normal cracks, increase of the width opening and the growth of deflections. With 0.9 of the destructive load, the beginning of flowability of metal armature was registered, which led to a rapid increase in the width of the cracks opening, significant increase in deflections and the destruction of samples with the cracking of concrete in the compressed zone. The moment of the beginning of metal armature flowability was considered as starting point of the destruction of the tested beams.

Due to the reduced modulus of BFRP, the series BB, BBD proved to be more deformative than the beams of the BM, BMD series. The appearance of the first normal cracks was recorded at a loading level of 0.1-0.2 of the destructive one. The further increase of the load resulted in the appearance of new normal cracks, and at the loading of 0.5-0.6 of the destructive one the sloping cracks began to appear. The location of the cracks was characterized by a uniform distribution with beam spacing of $100-150 \mathrm{~mm}$. The width of the cracks opening and deflections linearly increased with load increasing. It is typical for the structures reinforced by composite armature. The destruction of these samples was caused by fragmentation of the concrete in the compressed zone. The breakage or slipping of the BFRP rods was not registered.

Work of the beams of the series BMB, BMBD under load can be divided into two stages - before the beginning of flowability of metal armature and after it. The first normal cracks arose at a loading level of $0.2-0.3$ of a destructive one. To the level of loads $0.4-0.5$ of the destructive one the beam worked similarly to the beams of the series BM, BMD. The latter is due to the prevailing influence of metal armature. The further increase in load resulted in the appearance of the armature flowability. At this stage, the main resistance to the load is made by BFRP armature. The character of the work of the beam is similar to the work of the beams of the series BB, DBD - the number and width of the opening of cracks increases and the deflections grow. The destruction of the samples occurred due to the crushing of the concrete of the compressed zone with the simultaneous complete or partial 
breaking of the fibers of the BFRP armature. In Fig. 4 it is shown the general view of the ruined beam sample of the $\mathrm{BMB}$ series and the complete and partial breaking of the extended BFRP armature of this sample.

Durability indicators of tested beams by series are given in Table 3.

a)

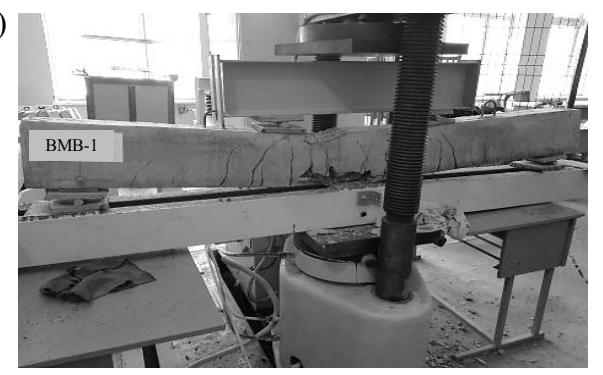

b)

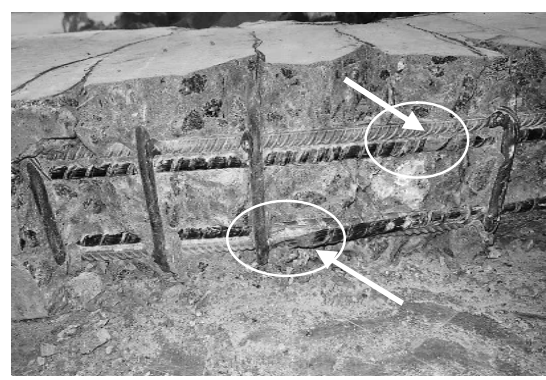

Fig. 4. Ruined beam sample of BMB series: a) General view; b) Complete or partial breaking of fibers of BFRP armature.

Table 3. Parameters of durability of samples of beams.

\begin{tabular}{|c|c|c|c|}
\hline $\begin{array}{c}\text { Series of } \\
\text { beams }\end{array}$ & $\begin{array}{c}\text { Destructive effort, } \\
\mathrm{kN}\end{array}$ & $\begin{array}{l}\text { Average destructive } \\
\text { effort, } F_{\mathrm{u},}, \mathrm{kN}\end{array}$ & $\begin{array}{l}\text { Relative durability } \\
\text { value, } F_{\mathrm{ui}} / F_{\mathrm{u}}\end{array}$ \\
\hline BM-1 & $69.16^{*}$ & \multirow{3}{*}{$70.22^{*}$} & \multirow{3}{*}{$x_{0}$} \\
\hline BM-2 & $69.9^{*}$ & & \\
\hline BM-3 & $71.61 *$ & & \\
\hline BMD-1 & $73.58 *$ & \multirow{3}{*}{$75.87^{*}$} & \multirow{3}{*}{1.08} \\
\hline BMD-2 & $74.56^{*}$ & & \\
\hline BMD-3 & $79.46^{*}$ & & \\
\hline BB-1 & 98.1 & \multirow{3}{*}{100.88} & \multirow{3}{*}{1.43} \\
\hline BB-2 & 95.65 & & \\
\hline BB-3 & 108.89 & & \\
\hline BBD-1 & 104.23 & \multirow{3}{*}{101.17} & \multirow{3}{*}{1.44} \\
\hline BBD-2 & 98.1 & & \\
\hline BBD-3 & $85.84 * *$ & & \\
\hline BMD-1 & $93.2\left(44.15^{*}\right)$ & \multirow{3}{*}{$96.1(45.13 *)$} & \multirow{3}{*}{1.38} \\
\hline BMB-2 & $98.1(49.05 *)$ & & \\
\hline BMB-3 & $96.87\left(42.18^{*}\right)$ & & \\
\hline BMBD-1 & $98.1(47.09 *)$ & \multirow{3}{*}{$99.24\left(49.7^{*}\right)$} & \multirow{3}{*}{1.41} \\
\hline BMBD-2 & $100.55(51.99 *)$ & & \\
\hline BMBD-3 & $99.08(50.03 *)$ & & \\
\hline
\end{tabular}

Notes:

1. $F_{\mathrm{u}}$ - destructive force of the beams of the series BM;

2.* - an effort that corresponds to the beginning of flowability of metal armature.

3 . $^{* *}$ - the datum is not considered when calculating the average destructive load.

The analysis of the data presented in Table 3 indicates that replacement of metal armature by BFRP armature has led to increase in the bearing power of the beam samples by $37-44 \%$ depending on the series. In the beams of BMB, BMBD series with the hybrid reinforcement, the part of BFRP armature was replaced by metal armature that had no impact on their bearing power. The durability increase compared with the beams of the BMW series is $38-41 \%$. This indicates that there are no reasons against the using of hybrid reinforcement of the bending structures from the perspective the performance of the bearing power. 
Use of the fine aggregate of MBC for producing concrete for the beams of the BMD, $\mathrm{BBD}, \mathrm{BMBD}$ series did not significantly impact the marginal durability. The beams of the $\mathrm{BMD}, \mathrm{BMBD}, \mathrm{BBD}$ series showed an increase in the bearing power from $1 \%$ to $8 \%$. This can be explained by higher roughness of the surface of grains of MBC wastes compared with quartz sand and suggests the possibility of efficient replacement of quartz sand by cheaper industrial wastes.

In Fig. 5 a general view of broken samples of beams is shown. Careful examination reveals that samples of the BM series (Fig.5, a) have significant residual deformation, samples of the BMB series (Fig. 5, b) are smaller. In the samples of the BB series the deformations are absent (Fig. 5, c). Flowability of the metal armature results in the significant residual structural deformations, which makes them unrebuildable. Due to the elastic performance of BFRP armature, the samples of the BB series did not have residual deformations, even after the destruction of the compressed zone concrete. This property of BFRP reinforcement can provide greater reliability of structures under the influence of overloads (earthquakes, accidents, etc.) due to the restoration of the design position after the cessation of power influences, even with significant damage. The latter statement needs further study by conducting appropriate experimental tests.

a)

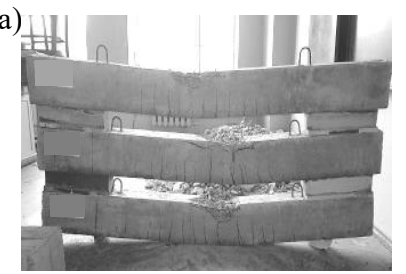

b)

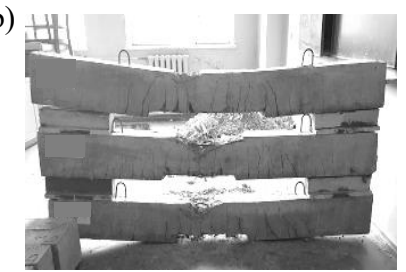

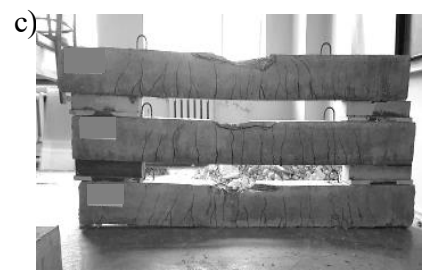

Fig. 5. General view of ruined samples of beams: a) Series BM; b) Series BMB; c) Series BB.

\section{Conclusions and recommendations}

\subsection{Conclusions}

The carried out experimental research of concrete beams with different types of reinforcement allows drawing the following conclusions:

- replacement of metal armature by BFRP armature allowed increasing the bearing ability of the samples of beams by $37-44 \%$;

-use of hybrid reinforcement allowed to improvement of the deformation characteristics of beams in comparison with the reinforcement of the BFRP armature, and did not cause a decrease in their bearing ability (durability increase was made $38-41 \%$ );

-elastic work of BFRP results in the absence of residual structural deformations of the structure after the load decreasing despite the insignificant damage and concrete destruction;

- fine fractionated MBC wastes are an effective replacement of quartz sand in the manufacture of concrete mixture.

\subsection{Recommendations}

The given results can be used for the development of the program of additional experimental tests of bending structures with hybrid reinforcement using metal and BFRP armature to determine the optimal ratios of different types of armature, as well as to developing recommendations for the design of such structures. 


\section{References}

1. M. Wang, Z. Zhang, Y. Li, M. Li, Z. Sun, Chemical Durability and Mechanical Properties of Alkali-proof Basalt Fiber and its Reinforced Epoxy Composites. Journal of Reinforced Plastics and Composites 27(4), 393-407, (2008).

2. B. Pouya, "Experimental investigation of the mechanical and creep rupture properties of basalt fiber reinforced polymer (bfrp)", PhD thesis, University of Akron, the USA, 216, (2011).

3. O. S. Soldatchenko, "Durability, rigidity and crack resistance of bending structures with glass fiber reinforced polymer and basalt fiber reinforced polymer", $\mathrm{PhD}$ thesis, Kyiv, Ukraine, 196, (2012).

4. T. Ovitigala and M. Issa, Flexural behavior of concrete beams reinforced with basalt fiber reinforcement polymer (BFRP) bars. Paper presented at the 11th International Symposium on Fiber Reinforced Polymer for Reinforced Concrete Structures, Guimarães, Portugal (2013).

5. D. Pawłowski and M. Szumigała, Flexural behavior of full-scale basalt FRPRC beamsexperimental and numerical studies. Procedia Engineering, 108, 518-525 (2015).

6. K. L. Kudyakov, V. S. Plevkov and A. V. Nevskii, Strength and deformability of concrete beams reinforced by non-metallic fiber and composite rebar, IOP Conf. Series: Materials Science and Engineering 71/1/012030, (2015).

7. A. A. Suzan Mustafa, A. Hilal Hassan, Behavior of concrete beams reinforced with hybrid steel and FRP composites, HBRC Journal, Housing and Building National Research Center [Electronic resource] (2017). - Mode of access: https://doi.org/10.1016/j.hbrcj.2017.01.001.

8. Akiel Mohammad, El-Maaddawy Tamer, El Refai Ahmed, Flexural tests of continuous concrete slabs reinforced with basalt fiber-reinforced polymer bars, CSCE 2016 Resilient Infrastructure, London, Ontario, 1-7, (2016).

9. G. Naveen Kumar, Karthik Sundaravadivelu, "Experimental Study On Flexural Behaviour Of Beams Reinforced With GFRP Rebars". IOP Conference Series: Earth and Environmental Science, 80, 1-11, (2017).

10. S. Vivekanand, A. Sumathi, "Static Behaviour of Concrete Beams Reinforced in Shear with GFRP Bars". International Journal of ChemTech Research, 8, 2, 635-642, (2015).

11. E. Mohamed, "Behaviour of continuous concrete slabs reinforced with frp bars", $\mathrm{PhD}$ thesis, University of Bradford, UK, 177, (2013).

12. L. I. Storozhenko, B. N. Shevchenko, V. M. Ilienko, Zhelezobetonnyie konstruktsii iz betona na othodah gornorudnoy $i$ metallurgicheskoy promyishlennosti. - Kyev: Budivelnyk, - 72, (1982). 